Supplement 4, Band 28,

Oktober 2005

\section{Zielgerichtete Tumortherapie}

Herausgeber

C. Bokemeyer, Hamburg

W.E. Berdel, Münster 
2 Vorwort: "Targeted therapy in oncology" - von der Forschung zur klinischen Praxis

C. Bokemeyer, J. Panse (Hamburg), W.E. Berdel (Münster)

4 Aktive Immuntherapie bei Patienten mit hämatologischen und soliden Neoplasien

H. Mellstedt (Stockholm), H. Veelken (Freiburg i.Br.)

9 Passive Immuntherapie mit monoklonalen Antikörpern

C. Bokemeyer, J. Panse (Hamburg)

14 Grundlagen der Signaltransduktion

Y. Yarden (Rehovot)

18 EGF-Rezeptorblockade mit monoklonalen Antikörpern und so genannten «small molecules"

F. Ciardiello (Neapel), B. Ma (Hong Kong)

25 Stellenwert der Angiogenese-Inhibition bei Tumorerkrankungen - präklinische Daten

W.E. Berdel (Münster), J. Panse (Hamburg)

29 Angiogenese-Hemmung durch Proteine, Peptide und "small molecules»: Klinischer Einsatz

G. Jayson (Manchester), J.-P. Armand (Villejuif), W.E. Berdel (Münster)

35 Klinische Entwicklung zielgerichteter molekularer Krebstherapeutika

H. Zwierzina (Innsbruck), M. Borner (Bern)

40 Entwicklung der Protein-Microarray-Technik und Nutzung im Rahmen einer individualisierten molekularen Tumortherapie

V. Espina (Manassas)

43 Stellenwert der Signaltransduktionshemmung und epigenetischer Therapiekonzepte in der Krebstherapie

J. Tabernero (Barcelona), S. Kaye (Sutton)

II Impressum

\section{KARGER}

Fax +49 7614520714

E-mail

Information@Karger.de 